\title{
Glycothermal preparation of potassium niobate ceramic particles under supercritical conditions
}

\author{
Chung-Hsin Lu*, Shih-Yen Lo, Yueh-Lu Wang \\ Department of Chemical Engineering, National Taiwan University, Taipei, Taiwan, ROC
}

Received 5 August 2001; accepted 1 October 2001

\begin{abstract}
Potassium niobate $\mathrm{KNbO}_{3}$ particles were synthesized via a newly developed glycothermal process using isopropanol as the reaction medium in supercritical environment. Increasing the concentration of $\mathrm{KOH}$ and the molar ratio of $\mathrm{K}^{+} / \mathrm{Nb}^{5+}$ substantially facilitated the formation of $\mathrm{KNbO}_{3}$. When the concentration was $0.5 \mathrm{M}$ and the molar ratio of $\mathrm{K}^{+} / \mathrm{Nb}^{5+}$ was greater than 2:1, well crystallized monophasic $\mathrm{KNbO}_{3}$ was successfully produced at as low as $250{ }^{\circ} \mathrm{C}$. In comparison with the traditional hydrothermal process, the supercritical glycothermal process greatly reduced the required concentration of $\mathrm{KOH}$. This supercritical glycothermal process provides a new prospective approach for synthesizing electronic ceramic powders at low temperatures. (C) 2002 Elsevier Science B.V. All rights reserved.
\end{abstract}

Keywords: Potassium niobate; Particles; Glycothermal; Supercritical

\section{Introduction}

Potassium niobate $\mathrm{KNbO}_{3}$ is a ferroelectric material possessing high electro-optic and nonlinear optical coefficients [1,2]. It also exhibits a large bandgap, and its optical properties can be sensitively altered by the application of electric field. $\mathrm{KNbO}_{3}$ has been applied in optical waveguides and holographic storage systems because of its specific electro-optic properties [3-5]. A large number of research groups have studied the crystal growth and optical properties of $\mathrm{KNbO}_{3}$; however, investigation related to the preparation of $\mathrm{KNbO}_{3}$ powders is few. In the solid-state reaction, thorough mixing of reactants and high-temperature heat treatment for a prolonged period are required for synthesizing $\mathrm{KNbO}_{3}$ powders [6]. For improving the

\footnotetext{
* Corresponding author.
}

mixing state of reactants in solid-state reaction, different kinds of solution synthesis methods such as precipitation and sol-gel processes have been investigated $[7,8]$. However, these processes could not directly produce well-crystallized $\mathrm{KNbO}_{3}$, and the subsequent calcination at high temperatures after the preparation of the precursors is inevitable. To overcome the above drawbacks, the hydrothermal process has been developed by our group [9]. Well crystallized $\mathrm{KNbO}_{3}$ powders can be obtained from the hydrothermal reaction. However, while using water as the solvent in the hydrothermal process, a high concentration $(8 \mathrm{M})$ of $\mathrm{KOH}$ is required to synthesize $\mathrm{KNO}_{3}$. From the standpoint of industrial application, high $\mathrm{KOH}$ concentration is neither economical nor good for the production instruments.

In this study, a new glycothermal process for synthesizing $\mathrm{KNO}_{3}$ in supercritical isopropanol solution was developed. The supercritical fluid has a dissolv- 
ing ability similar to that of normal liquids but has better transport properties (such as viscosity, diffusivity, thermal conductivity, etc.) $[10,11]$; therefore, it is considered that the chemical reactions should be accelerated in supercritical environment. Furthermore, fine and dense particles will be formed because of the well dispersion state and high pressure of supercritical fluids [12]. The critical temperature $\left(T_{\mathrm{c}}\right)$ and pressure $\left(P_{\mathrm{c}}\right)$ of isopropanol are $235.3{ }^{\circ} \mathrm{C}$ and $47.0 \mathrm{~atm}$, respectively. In comparison with the critical conditions of water $\left(T_{\mathrm{c}}=374.4{ }^{\circ} \mathrm{C}\right.$ and $\left.P_{\mathrm{c}}=218.3 \mathrm{~atm}\right)$, both parameters of isopropanol are much lower than those of water. In consideration of the operation pressure and temperature limits of the autoclave, isopropanol was chosen as the reaction medium in the supercritical glycothermal process. The proper conditions for obtaining $\mathrm{KNbO}_{3}$ particles in the glycothermal reaction were determined in this study. The effects of the amounts of starting materials added in the reaction on the phase purity of $\mathrm{KNbO}_{3}$ powders were investigated. The influence of the reaction conditions on the morphology and particle size of the obtained $\mathrm{KNbO}_{3}$ powders were also examined.

\section{Experimental}

Reagent-grade potassium hydroxide solution and niobium oxide were used as the starting materials. Various amounts of potassium hydroxide were dissolved in isopropanol to adjust the concentrations of the potassium cation ranging from 0.05 to $0.5 \mathrm{M}$. The prepared potassium cation solutions were mixed with niobium oxide particles to form a mixed slurry. The mixing molar ratios of $\mathrm{K}^{+} / \mathrm{Nb}^{5+}$ were set to be $1: 1$, $2: 1,4: 1$, and $16: 1$. The mixed slurry was put into a teflon-lined autoclave apparatus, and was subjected to glycothermal reaction at $250{ }^{\circ} \mathrm{C}$. Under this condition, isopropanol turned into a supercritical fluid. In order to improve the mixing state, a mechanical stirrer was used under the high pressure condition, and the rotation speed was set at $300 \mathrm{rpm}$. After the glycothermal reaction, the obtained products were cooled to room temperature, and repeatedly washed with deionized water. The washed powders were then dried at around $50{ }^{\circ} \mathrm{C}$ in air. The compounds present in the dried powders were analyzed by X-ray powder diffraction (XRD). The microstructural development and particle size of the powders were examined by scanning electron microscopy (SEM).

\section{Results and discussion}

The molar cation ratio $\mathrm{K}^{+} / \mathrm{Nb}^{5+}$ was fixed at $1: 1$, and different concentrations of potassium cation solutions were reacted with niobium oxide at $250{ }^{\circ} \mathrm{C}$ in isopropanol for $2 \mathrm{~h}$. Since the reaction temperature was higher than the critical temperature of isopropanol, this glycothermal reaction has taken place in a supercritical environment. After the reactions, the obtained products were examined by XRD and the obtained patterns are illustrated in Fig. 1. From the XRD analysis, it is found that crystallized $\mathrm{KNbO}_{3}$ can be directly synthesized under the supercritical condition of isopropanol; however, the amounts of $\mathrm{KNbO}_{3}$ significantly depend on the concentration of $\mathrm{KOH}$. When the concentration of $\mathrm{KOH}$ equaled $0.05 \mathrm{M}$, only a small amount of $\mathrm{Nb}_{2} \mathrm{O}_{5}$ reacted with $\mathrm{KOH}$ to form $\mathrm{KNbO}_{3}$, leaving the majority of $\mathrm{Nb}_{2} \mathrm{O}_{5}$ not participating in the reaction. When the concentration of $\mathrm{KOH}$ rose to $0.1 \mathrm{M}$, the amount of $\mathrm{KNbO}_{3}$ slightly increased. With $0.3 \mathrm{M}$ $\mathrm{KOH}, \mathrm{KNbO}_{3}$ became the major compound in the

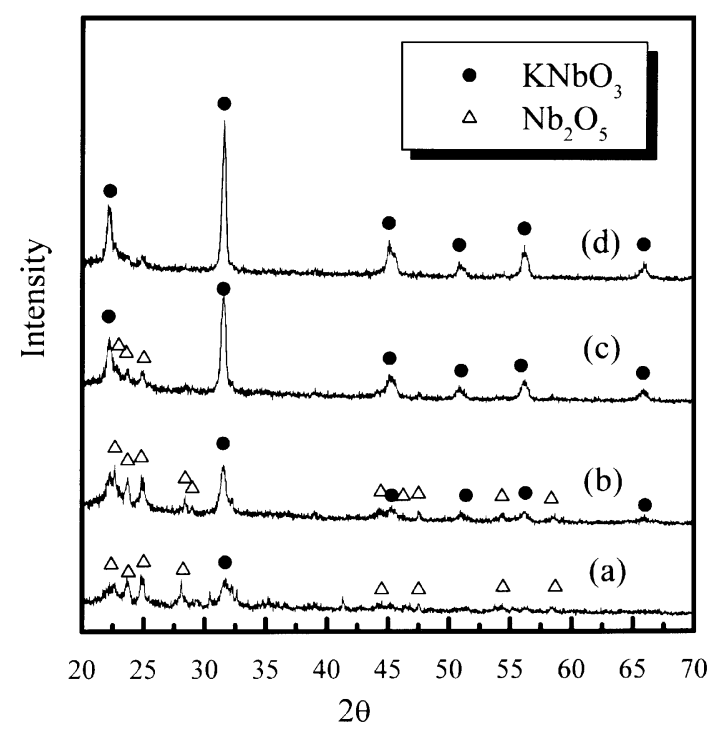

Fig. 1. X-ray diffraction patterns of glycothermal prepared $\mathrm{KNbO}_{3}$ powders at $250{ }^{\circ} \mathrm{C}$ using $[\mathrm{KOH}]$ equal to (a) 0.05 , (b) 0.1 , (c) 0.3 , and (d) $0.5 \mathrm{M}$. The molar cation ratio $\mathrm{K}^{+} / \mathrm{Nb}^{5+}$ was fixed at $1: 1$. 
products. When the concentration of $\mathrm{KOH}$ increased to $0.5 \mathrm{M}$, the amount of $\mathrm{KbNO}_{3}$ was further increased; however, a small amount of $\mathrm{Nb}_{2} \mathrm{O}_{5}$ still existed in the samples.

The microstructures of the obtained powders are shown in Fig. 2. At $[\mathrm{KOH}]=0.05 \mathrm{M}$, most of the products were $\mathrm{Nb}_{2} \mathrm{O}_{5}$ particles, exhibiting an irregular morphology with a particle size of $0.7-1.5 \mu \mathrm{m}$ (Fig. 2(a)). When the concentration of $\mathrm{KOH}$ rose to $0.1 \mathrm{M}$, the particle size of $\mathrm{Nb}_{2} \mathrm{O}_{5}$ particles became smaller, and the other type of particles with a cubic morphology appeared in the specimens (Fig. 2(b)). It implies that $\mathrm{Nb}_{2} \mathrm{O}_{5}$ particles were partially dissolved in isopropanol, and $\mathrm{KNbO}_{3}$ particles with an idiomorphic shape were formed. As the concentration of $\mathrm{KOH}$ further increased to $0.3 \mathrm{M}$, a majority of $\mathrm{Nb}_{2} \mathrm{O}_{5}$ particles disappeared, and cubic $\mathrm{KNbO}_{3}$ particles in large quantity were produced. The above results reveal that the concentration of $\mathrm{KOH}$ is a critical controlling factor for synthesizing $\mathrm{KNbO}_{3}$. At a low concentration of $\mathrm{KOH}$, $\mathrm{Nb}_{2} \mathrm{O}_{5}$ hardly reacted with $\mathrm{KOH}$. When the concentration of $\mathrm{KOH}$ increased, $\mathrm{Nb}_{2} \mathrm{O}_{5}$ could be dissolved in $\mathrm{KOH}$ and reacted with $\mathrm{KOH}$. Raising the concentration of $\mathrm{KOH}$ tends to increase the solubility of $\mathrm{Nb}_{2} \mathrm{O}_{5}$ in isopropanol, thereby facilitating the formation of $\mathrm{KNbO}_{3}$.

For eliminating the residual $\mathrm{Nb}_{2} \mathrm{O}_{5}$ and facilitating the complete formation of $\mathrm{KNbO}_{3}$, the molar ratio of $\mathrm{K}^{+} / \mathrm{Nb}^{5+}$ was increased. The molar ratio of $\mathrm{K}^{+} /$ $\mathrm{Nb}^{5+}$ ranged from 1:1 to $16: 1$, and the concentration of $\mathrm{KOH}$ was fixed at $0.5 \mathrm{M}$. After the glycothermal reaction at $250{ }^{\circ} \mathrm{C}$ for $2 \mathrm{~h}$, the obtained products were examined by XRD. As shown in Fig. 3, when $\mathrm{K}^{+} /$ $\mathrm{Nb}^{5+}$ molar ratio was 2:1, a small amount of $\mathrm{Nb}_{2} \mathrm{O}_{5}$ still coexisted with $\mathrm{KNbO}_{3}$. On the other hand, when $\mathrm{K}^{+} / \mathrm{Nb}^{5+}$ was increased to $4: 1$ and $16: 1$, a monophasic $\mathrm{KNbO}_{3}$ compound was successfully obtained. These results demonstrate that the developed glycothermal process can successfully produce well crystallized $\mathrm{KNbO}_{3}$ particles without the need of subsequent calcination. In the conventional hydrothermal method using water as the reaction medium, the concentration of $\mathrm{KOH}$ has to be as high as $8 \mathrm{M}$ for inducing the

Fig. 2. Scanning electron micrographs of glycothermal prepared $\mathrm{KNbO}_{3}$ powders at $250{ }^{\circ} \mathrm{C}$ using $[\mathrm{KOH}]$ equal to (a) 0.05 , (b) 0.1 , and (c) $0.5 \mathrm{M}$.

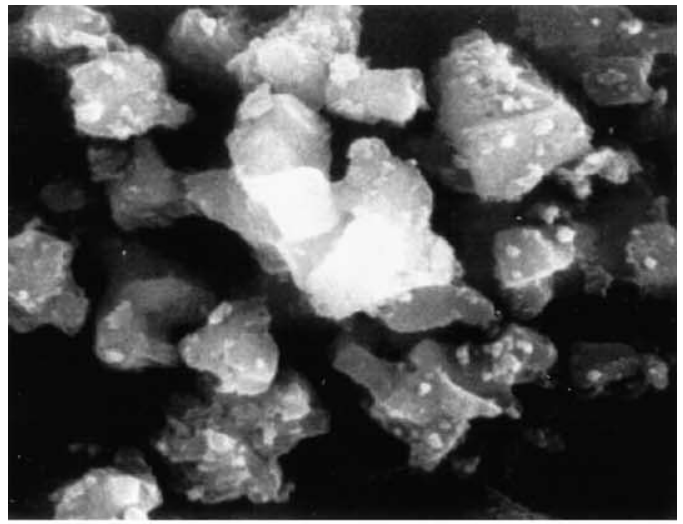

(a)

$\mathbf{1} \mu \mathbf{m}$
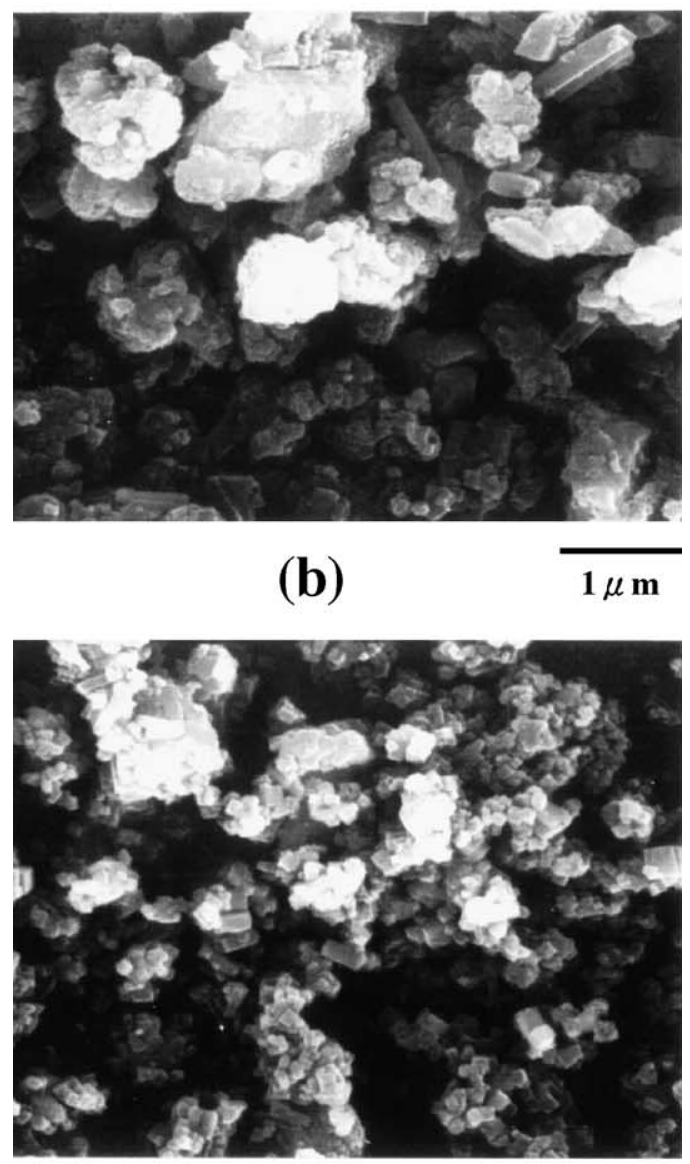

(c)

$\mathbf{1} \mu \mathbf{m}$ 


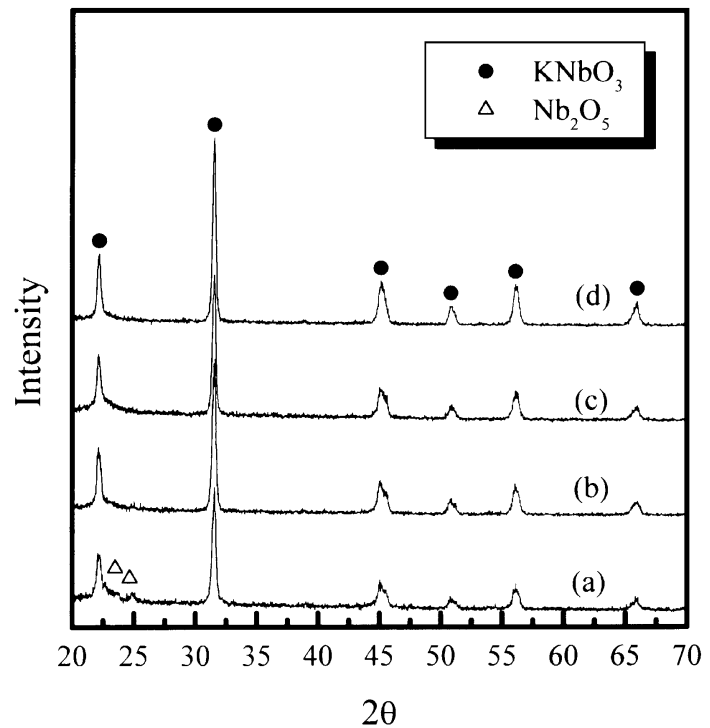

Fig. 3. X-ray diffraction patterns of glycothermal prepared $\mathrm{KNbO}_{3}$ powders at $250{ }^{\circ} \mathrm{C}$ at the molar cation ratio $\mathrm{K}^{+} / \mathrm{Nb}^{5+}$ equal to (a) $1: 1$, (b) $2: 1$, (c) $4: 1$, and (d) $16: 1 .[\mathrm{KOH}]$ was fixed at $0.5 \mathrm{M}$.

reaction between $\mathrm{Nb}_{2} \mathrm{O}_{5}$ and $\mathrm{KOH}$ [9]. On the contrary, the glycothermal reaction under supercritical conditions in this study merely required $\mathrm{KOH}$ at significantly lower concentration. It is regarded that the supercritical fluid improves the dissolution of reactants and enhances the reaction kinetics, thereby facilitating the formation of $\mathrm{KNbO}_{3}$.

The microstructures of the $\mathrm{KNbO}_{3}$ particles synthesized at different molar ratios of $\mathrm{K}^{+} / \mathrm{Nb}^{5+}$ are shown in Fig. 4. All formed $\mathrm{KNbO}_{3}$ particles were near equalaxial and exhibited a cubic morphology, which resembled that of hydrothermally, derived $\mathrm{KNbO}_{3}$ particles at high concentration of $\left[\mathrm{Nb}^{5+}\right]$ [9]. In addition, it is found that the particle size of $\mathrm{KNbO}_{3}$ prepared in the glycothermal process increased with a rise in the amount of potassium cations. When the molar ratio of $\mathrm{K}^{+} / \mathrm{Nb}^{5+}$ rose from $1: 1$ to $16: 1$, the particle size of $\mathrm{KNbO}_{3}$ particles increased from 0.1 to $0.3 \mu \mathrm{m}$. Compared with the solid-state reaction, sol-gel, precipitation, and hydrothermal processes [7-9], it can be confirmed that the glycothermal process significantly

Fig. 4. Scanning electron micrographs of glycothermal prepared $\mathrm{KNbO}_{3}$ powders at $250{ }^{\circ} \mathrm{C}$ at the molar cation ratio $\mathrm{K}^{+} / \mathrm{Nb}^{5+}$ equal to (a) $1: 1$, (b) $2: 1$, and (c) $16: 1$.
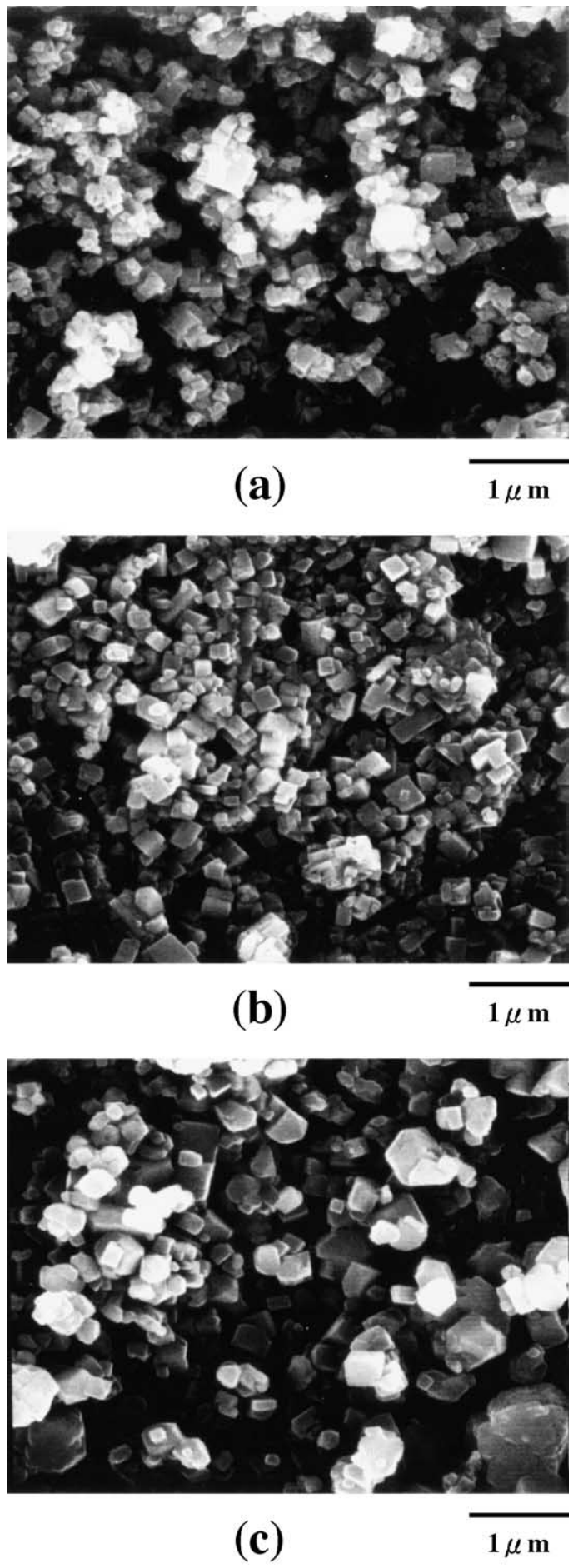
reduces the required heating temperature for obtaining pure $\mathrm{KNbO}_{3}$ powders.

For further elucidating the formation of $\mathrm{KNbO}_{3}$, the reaction time during the glycothermal process was varied. The concentration of $\mathrm{KOH}$ solution was $0.5 \mathrm{M}$ and the molar ratio of $\mathrm{K}^{+} / \mathrm{Nb}^{5+}$ was $4: 1$. It was found that there was no $\mathrm{KNbO}_{3}$ formed at the beginning of glycothermal reaction. However, at $0.5 \mathrm{~min}$ after the onset of the reaction, a small amount of $\mathrm{KNbO}_{3}$ particles began to form. After reaction for $5 \mathrm{~min}$, the amount of $\mathrm{KNbO}_{3}$ was rapidly increased. When the reaction time was prolonged to $15 \mathrm{~min}$, a large amount of well crystallized $\mathrm{KNbO}_{3}$ was formed. The above results reveal that the formation of $\mathrm{KNbO}_{3}$ particles is significantly enhanced in the supercritical environment and the nuclei of $\mathrm{KNbO}_{3}$ can be produced within a short reaction period. The developed glycothermal reaction not only significantly lowers the synthesis temperature of $\mathrm{KNbO}_{3}$, but also greatly curtails the reaction time. This process is considered to be a highly potential method for synthesizing other electronic ceramic powders.

\section{Conclusions}

(i) A new glycothermal process has been developed for synthesizing $\mathrm{KNbO}_{3}$ powders using isopropanol as the reaction medium in supercritical environment.

(ii) The phase purity of $\mathrm{KNbO}_{3}$ significantly depends on the concentration of $\mathrm{KOH}$ and the molar ratio of $\mathrm{K}^{+} / \mathrm{Nb}^{5+}$. When the concentration was $0.5 \mathrm{M}$ and the molar ratio of $\mathrm{K}^{+} / \mathrm{Nb}^{5+}$ was larger than $2: 1$, well crystallized monophasic $\mathrm{KNbO}_{3}$ was successfully produced at as low as $250{ }^{\circ} \mathrm{C}$. In comparison with the traditional hydrothermal process, the supercritical glycothermal process greatly decreased the required concentration of $\mathrm{KOH}$.

(iii) The formed $\mathrm{KNbO}_{3}$ particles were near equalaxial and exhibited a cubic morphology and submicron sizes. In addition, the particle size of $\mathrm{KNbO}_{3}$ increased with a rise in the amount of potassium cations.

(iv) The developed glycothermal process is considered to be a highly potential method for synthesizing electronic ceramic powders at relatively low temperatures within a short reaction period.

\section{Acknowledgements}

We acknowledge Hsin-Cheng Hong for his assistance with the drawing of figures.

\section{References}

[1] G. Shirane, H. Danner, A. Pavlovic, R. Pepinsky, Phys. Rev. 93 (1954) 672.

[2] S.K. Kurtz, T.T. Perry, J. Appl. Phys. 39 (1968) 3798.

[3] P. Gunter, Phys. Rep. 93 (1982) 199.

[4] M.K. Chun, L. Goldberg, J.F. Weller, Appl. Phys. Lett. 53 (1988) 1170.

[5] B.A. Tuttle, Mater. Res. Soc. Bull. 12 (1987) 40.

[6] U. Fluckiger, H. Arend, H.R. Oswald, J. Am. Ceram. Soc. 56 (1977) 575.

[7] K.J. Kim, E. Matijevic, J. Mater. Res. 7 (1992) 912.

[8] M.M. Amni, M.D. Sacks, J. Am. Ceram. Soc. 74 (1991) 53.

[9] C.H. Lu, S.Y. Lo, Mater. Lett. 34 (1998) 172.

[10] U. van Wasen, I. Swaid, G.M. Schneider, Angew. Chem., Int. Ed. Engl. 14 (1980) 167.

[11] N. Ajzenberg, F. Trabelsi, F. Recasens, Chem. Eng. Technol. $23(2000) 829$.

[12] C. Pommier, K. Chhor, J.F. Bocquet, M. Barj, Mater. Res. Bull. 25 (1990) 213. 